\title{
AS MULHERES COMO PILAR DA CONSTRUÇÃO DOS PROGRAMAS SOCIAIS
}

\author{
Yumi Garcia dos Santos*
}

\begin{abstract}
Este artigo analisa o modo como as políticas públicas voltadas para a saúde e a assistência social no Brasil se consolidam a partir da centralidade da atuação das mulheres pobres. Por meio de uma pesquisa qualitativa e de análise das trajetórias das usuárias e das agentes de ponta dos ditos "novos" programas sociais brasileiros, pretende-se mostrar que o sucesso que tais programas têm conquistado depende, em grande medida, da atuação dessas mulheres mediadoras dentro da lógica conservadora da divisão sexual do trabalho e da disposição feminina para o cuidado. Em particular, as agentes, em contraponto às usuárias, têm acesso à mobilidade social que as tira do confinamento na esfera privada pela sua presença no mercado de trabalho. No entanto, o maior ganho dessa mobilização feminina a baixo custo e de alta produtividade é direcionado às instituições gestoras dos "novos" programas sociais em questão, desde as organizações filantrópicas até os governos.
\end{abstract}

Palavras-Chave: "Novos" programas sociais. Mediação feminina. Família. Trabalho. Divisão sexual do trabalho.

\section{APRESENTAÇÃO}

Este artigo analisa, com o olhar voltado para as relações sociais de gênero, o modo como as políticas públicas voltadas para a saúde e a assistência social no Brasil se consolidam a partir da centralidade da atuação das mulheres pobres, nos programas implementados como profissionais e usuárias. ${ }^{1}$ Por meio dessa análise, pretende-se mostrar que a existência e o sucesso que tais programas têm mostrado dependem da atuação dessas mulheres dentro da lógica conservadora da divisão sexual e social do trabalho.

\footnotetext{
* Socióloga. Doutora em Sociologia. Professora Adjunta do Departamento de Sociologia da Universidade Federal de Minas Gerais (UFMG).

Av. Presidente Antônio Carlos, 6627. Cep: 31270-901. Pampulha - Belo Horizonte - Minas Gerais. yumigds@ uol.com.br

${ }^{1} \mathrm{O}$ artigo baseia-se na pesquisa de pós-doutorado de Yumi Garcia dos Santos, no Centro de Estudos da Metrópole (CEM), com o financiamento do Fundo de Amparo à Pesquisa do Estado de São Paulo (FAPESP) (2009-2011). Ela fez igualmente parte do Projeto Latinassist (ANR, França) entre 2011e 2014. A pesquisa de campo, que abrangeu observação participante e entrevistas em profundidade, foi realizada entre abril de 2010 e junho de 2011, em parceria com Isabel Georges (Institut de Recherche pour le Dévelopement (IRD-DEVSOC) e Universidade Federal de São Carlos (UFSCar-DS).
}

No início dos anos noventa, a população historicamente abandonada pelo Estado começa a assistir a uma inédita presença do poder público por meio da inclusão em programas e serviços sociais. Como vem sido discutido na literatura a respeito (Tatagiba, 2006; Lavalle et alii., 2007; e Feltran, 2011), essa transformação viria acompanhada de uma retração dos movimentos sociais e de uma aproximação da sociedade civil com a política e a administração. Do ponto de vista da religião, a teologia da libertação dá lugar às igrejas evangélicas. É nesse contexto que a população que estudamos tornou-se "beneficiária" dos "novos" programas sociais como profissionais e usuários da Estratégia Saúde Família (ESF), ${ }^{2}$ serviço do Ministério da Saúde, e o Programa Ação Família (PAF), programa de assistência social do município de São Paulo. ${ }^{3}$

${ }^{2}$ O ESF é um serviço descentralizado em nível municipal,
que promove a prevenção e a identificação de doenças,
assim como a educaça sanitária (Oliveira 2004, p. 47).
O serviço é oferecido nas Unidades Básicas de Saúde por
meio de equipes médicas constituídas por um médico, um
enfermeiro, dois auxiliares de enfermagem e cinco ou seis
agentes comunitários de saúde (Ministério da Saúde).
${ }^{3}$ O Programa Ação Família (PAF) é um programa de assis-
tência às famílias que tomou como modelo operacional o
Chile Solidario e a ESF. Em 2011, foi reformulado como 
Programas e serviços sociais voltados para as famílias têm se constituído, nos últimos quinze anos, em método dominante de combate à pobreza e de proteção social nos países da América Latina em geral. Trata-se, por exemplo, do Chile Solidario do Chile, do Familias en Acción da Colômbia, do programa Progresa/Oportunidades do México, da Estratégia Saúde Família, do Programa Bolsa Família e do Serviço de Proteção e Atendimento Integral à Família do Brasil e suas diversas formas locais, como o PAF acima citado. Tais programas surgem como frutos do acúmulo de teorias sobre pobreza e desenvolvimento, que apontam para as dimensões que não se limitam à pobreza de renda, incluindo outros fatores de privação, como a relativa a direitos, trabalho, saúde, moradia, educação, segurança e vínculos sociais (Dagnino, 2000; Anderson, 1998; Sen, 1998; Rocha, 2006).

Uma das características peculiares dos programas sociais brasileiros, em contraponto aos de outros países latino-americanos, é a adoção da figura dos agentes de rua, de ponta, como os agentes comunitários de saúde (ACS) da ESF, e os agentes de proteção social (APS), do PAF (exceto Cuba, de onde foi inspirada a ESF). São formas profissionais adotadas pelos "novos" programas assistenciais em nosso país para atender à população em seu bairro e em seu domicílio, na perspectiva de garantir a capilaridade, a proximidade e a continuidade. São esses agentes e usuários dos programas, em sua grande maioria, mulheres, que se constituem em objeto referencial da pesquisa, pela particular posição que ocupam, na interface i entre o Estado e as famílias assistidas. Assim, $\dot{*}$ interroga-se o lugar da mulher na política soj cial contemporânea brasileira e suas relações com o Estado, levando em consideração sua condição de classe e gênero. Nossa hipótese de trabalho é que se configura uma gestão da

serviço - Servico de Assistência Social às Famílias -, para que a assistência social paulistana fosse executada conforme as diretrizes do Serviço de Atenção Integral às Famílias (PAIF) do Ministério do Desenvolvimento Social e Combate à Fome. assistência baseada na mobilização das mulheres pobres que se mostram dispostas ao trabalho do cuidado, em que não se faz ruptura com a "moral dos pobres" (Sarti, 1996) e se encontra afinidade com o desenho dos programas sociais contemporâneos.

\section{GESTÃO SEXUADA DO SOCIAL: o antigo e o novo}

Um exame da recente história das intervenções sociais nos faz constatar que a abordagem focalizada nas famílias é uma estratégia de intervenção do Estado nas camadas pobres que remonta aos séculos XVIII-XIX, no processo da modernização ocidental. Michel Foucault (2004: 194-195) afirma que a promoção da vida pela prática coletiva da medicina já vinha sendo preparada a partir do século XVIII, época em que se passou a privilegiar a saúde da criança por intermediação das famílias. Diferentemente do Antigo Regime, passa-se a visar à população - principalmente a população pobre - para investir na sua utilidade (id.: 198). É nesse contexto que se forma a família das camadas populares, onde o homem deve ser um trabalhador responsável pela renda familiar e a mulher dona de casa que supervisiona de perto as funções de cada membro da família.

Segundo Jacques Donzelot (1977, 2005, p. 42), uma "estratégia de familiarização" das camadas populares apoiada na figura materna foi levada a cabo no contexto europeu da segunda metade do século XIX. As jovens mulheres eram encorajadas pelos moralistas da época a sair dos conventos e da prostituição - as opções possíveis para as pobres - para exercer atividades profissionais que ajudassem a desenvolver suas competências domésticas, com o objetivo de se preparar para o casamento (id.). Sem a concorrência com as mulheres, os homens puderam garantir sua frágil posição no mercado de trabalho; ademais, puderam contar com as atividades reprodutivas assumidas por suas companheiras, dedicando-se ex- 
clusivamente ao trabalho produtivo. O trabalho feminino era visto como uma necessidade ocasional, de modo a assegurar a sobrevivência material da família. Assim, os papéis sociais de homens e mulheres da classe popular foram redistribuídos e disciplinados. Os homens se constituíram como provedores e chefes do lar (o que permitiu o resgate do poder patriarcal enfraquecido), e as mulheres como responsáveis pelas atividades domésticas e educativas, inclusive a vigilância do marido para que ele não se desviasse da sua função de chefe de família (id.: p. 43). No que se referia às crianças, tratava-se de evitar a séria questão do abandono e da negligência, que resultava frequentemente na vagabundagem e na prostituição (id.: p. 2627). Amparadas pelas moradias sociais e outras instituições de apoio, como a escola e a educação higienista, as mulheres foram centrais para manter os homens e as crianças no ambiente aconchegante do lar (id.). Assim, é possível afirmar que a família da classe popular é uma construção social que teve como principal pilar as mulheres pobres como donas de casa competentes, boas esposas e mães responsáveis. Da mesma forma, a figura materna veio a ser a melhor aliada dos especialistas como médicos e higienistas do século XIX, que lhe atribuíram o poder de impor sua autoridade em casa como educadora e sua auxiliar (id.: p. 24-25).

Segundo Margareth Rago (1985, p. 75), o discurso direcionado à mulher para que fosse dona de casa competente, boa esposa e mãe responsável operava de modo fortemente similar no Brasil entre o final do Império e o início da República (final do século XIX). Visava-se à vigilância do comportamento sexual das mulheres, tendo como hipótese constante e latente de que a mulher pobre tendia a se prostituir. As intervenções dos higienistas nas famílias pobres eram legitimadas pela necessidade de conter as doenças venéreas (Rago, op. cit.: p. 87), além das epidemias como a febre amarela e a peste bubônica (Sposati, 1988, p. 101). Com o avanço da industrialização nos meados do século XX, organiza-se, de modo similar ao da camada popular europeia, a família da classe trabalhadora brasileira.

De acordo com Sarti (1996), ela supõe que os papéis do marido e da esposa sejam cumpridos de forma hierarquizada e complementar, o que permite "realizar diferentes funções da autoridade na família": o homem, a de pai e chefe de família, e a mulher, a de mãe e dona de casa. O chefe de família seria a "autoridade moral, responsável pela respeitabilidade familiar" e hierarquicamente superior, enquanto a dona de casa se responsabilizaria pela manutenção da "unidade do grupo", submetida ao primeiro. A propriedade biológica feminina da reprodução naturaliza sua inclinação para as atividades do cuidado dos membros da família. Como afirma Sarti (id.: p. 43), "a autoridade feminina vincula-se à valorização da mãe, num universo simbólico em que a maternidade faz da mulher, mulher, tornando-a reconhecida como tal, senão ela será uma potencialidade, algo que não se completou”. Assim, o casamento das mulheres da camada pobre envolve, em ampla medida, a obtenção de um status respeitável por meio da combinação dos seus papéis de esposa, dona de casa e, principalmente, mãe.

As intervenções do Estado por meio dos novos programas de proteção social possui um duplo sentido para a população, entre o cuidado prestado pelo poder público, transmitido pela figura de um trabalhador social, e o controle. De um lado, é a manifestação de um Estado mais presente e ao alcance dos pobres, historicamente excluídos dos serviços e benefícios públicos (Sposati, 1988); de outro, tratase de atingir a população assistida em nível capilar e detectar quem se enquadra ou não nos critérios de receptividade dos benefícios cada vez mais ampliados, ${ }^{4}$ executando o "controle dos assistidos" (Dubois, 2009, p. 29; Georges e Santos, 2013, p. 173). A família que foi con-

${ }^{4}$ A mais recente ampliação dos beneficiários do Bolsa Família é a inclusão de mulheres grávidas e de lactantes, até que a criança atinja seis meses de idade, as quais recebem um valor de 32 reais. O objetivo da política da presidenta Dilma, o "Brasil Sem Miséria”, é ampliar o foco de atendimento à pobreza (MDS, 2011). 
templada por esses programas sociais passa a receber uma gama de orientações dos trabalhadores sociais - na grande maioria dos casos, do sexo feminino - para que faça uso correto dos serviços e dos benefícios.

Assim, combinando programas de proteção social e de combate à pobreza na forma de transferência de renda, marca dos governos de Lula e de Dilma, tem-se formado, no Brasil, uma categoria, entre a população pobre, a dos "beneficiários", como uma nova porta de entrada para a cidadania. A cidadania permanece, porém, "restrita e controlada pelo Estado", numa continuidade do que Wanderley Guilherme dos Santos chamou de "cidadania regulada", excluindo "qualquer conotação pública e universal” (1979, p. 102). Dessa vez, em vez dos direitos se limitarem aos trabalhadores formais, estendem-se à população beneficiária dos programas sociais.

Nesse contexto, a novidade trazida pelos programas contemporâneos é de que as mulheres pobres, como profissionais, passam a lograr visibilidade e a obter renda própria pela atuação numa função antes exercida no contexto da militância comunitária (Lima, 2008, 2009; Georges, 2011). A lei federal de 2002 reconhece a profissão de agente comunitário de saúde. ${ }^{5}$ A profissão é, contudo, caracterizada por uma série de ambivalências com as quais o trabalhador deve lidar: a de se situar na fronteira entre o emprego público e o emprego privado, por não possuir caráter estatutário; os agentes devem ser moradores do próprio território de atuação, sendo desligados da função quando se mudam da área; possuem um trabalho que i propicia status na comunidade, porém situado $\therefore$ na mais baixa hierarquia da equipe do prograస ma, inclusive do ponto de vista salarial (Lima e Moura, 2005). Possuem ainda a característica de serem, ao mesmo tempo, agentes moralizadores e objeto de controle social (id.), o que descarta a possibilidade de uma relação hierárquica clássica como a existente entre os agentes do Estado especializados (como os assisten-

${ }^{5}$ Lei federal $n^{\circ} 10.507$, de 10 de julho de 2002. tes sociais) e a população assistida. Exercidas por meio de visitas domiciliares, mantendo-se contato estreito e contínuo com a população atendida, trata-se de ocupações fortemente marcadas pelas características femininas do cuidado com as pessoas (trabalho do "care"), o que pode justificar a alta concentração de agentes do sexo feminino (id.).

Por outro lado, é uma figura feminina a mãe, principalmente - que frequentemente assume o papel de mediadora entre o Estado e a família, responsabilizando-se pela execução das orientações recebidas pelos trabalhadores sociais. A abordagem familista opera com um pressuposto: o ocultamento da diferença, da desigualdade, do conflito de gênero no seio da família, ou a ausência da percepção do que Sen (1990) chama de "conflitos cooperativos" (co -operative conflicts). O autor adverte que a família não é uma unidade homogênea que opera unicamente na lógica da solidariedade, contendo relações muitas vezes conflitantes entre os membros. Assim, o interesse do homem e o da mulher são frequentemente divergentes, o dos adultos é diferente do das crianças, o dos idosos difere dos demais, homens e mulheres. É dentro desses interesses conflitantes que a família vive o cotidiano, ora cooperando, ora entrando em conflito, preservando - ou não o equilíbrio entre seus membros. As políticas que priorizam as famílias operam como se tais conflitos e desigualdades intrafamiliares não existissem, tratando a família como uma unidade homogênea. Nesse caso, a mulher, que implicitamente deve ser a pessoa de referência para o atendimento pelos programas, é vista apenas como um agente funcional, uma representação da família.

Os serviços em questão apresentam também a característica de romper com as políticas ditas assistencialistas, incentivando a administração dos riscos pelos usuários por meio da "corresponsabilidade", por meio da qual as famílias são estimuladas a participar ativamente em prol do seu próprio desenvolvimento por meio do cumprimento das condicionalidades 
(Molyneux, op. cit.: p. 10). A participação nos programas é condicionada à presença escolar das crianças e é geralmente vinculada ao recebimento de programa de transferência de renda. Mais uma vez, embora não explícito, na prática, é a mulher, na condição de mãe, que executa as orientações dadas pelos programas e serviços para fortalecer os vínculos familiares e cumprir o dever parental de garantir a educação e a saúde das crianças, combatendo a reprodução da pobreza intergeracional.

No caso do município de São Paulo, a terceirização dos serviços assistenciais faz com que valores conservadores de gênero e família inerentes às confissões religiosas de cada organização conveniada se sobreponham ao desenho familista dos programas (Georges e Santos 2013). Tais valores são estruturantes na concretização das relações sociais no público e no privado, desde a direção das organizações até as usuárias, passando pelas profissionais de intervenção social, como as agentes, formando uma "cadeia feminina de produção de serviços" (id.).

\section{USUÁRIAS E TRABALHADORAS DOS “NOVOS" PROGRAMAS SO- CIAIS: juntas, mas separadas}

\section{As beneficiárias dos "novos" pro- gramas sociais: usuárias e agentes de rua}

A investigação de campo contou com duas técnicas principais: entrevistas semidiretivas e observações participantes. As entrevistas foram baseadas em história de vida e as observações participantes foram realizadas por meio de acompanhamento a visitas domiciliares com os agentes de rua, observação dos equipamentos existentes nos territórios, de reuniões socioeducativas e com grupos focalizados, assim como anotações de diálogos informais.

O método de análise é inspirado no método de análise biográfica desenvolvido por
Didier Demazière e Claude Dubar (2007). Ele procura extrair e classificar os elementos subjetivos e constitutivos de identidade dos indivíduos por meio da escuta e da análise de uma história contada (como um evento identitário, baseado na história vivida). Da mesma forma, procura-se recorrer à abordagem indutiva no processo de teorização a partir do trabalho de campo (Grounded Theory; id.: p. 8). Segundo os autores (id.: p. 38), os dados não "falam por si”; eles devem ser organizados a partir de uma preocupação de "produzir uma teoria do fenômeno estudado", ou seja, de descobrir a maneira como ele é construído a partir das interações entre os atores.

Entendemos que as onze mulheres aqui apresentadas são beneficiárias dos "novos" programas sociais em diferentes graus, como usuárias ou trabalhadoras. Todas moram nos territórios estabelecidos como áreas de intervenção dos programas, compondo a população -alvo. Quatro dentre elas se tornaram agentes de ponta dos programas como consequência da busca por um trabalho. Elas são igualmente mães com pelo menos um filho dependente, sendo que cinco dentre elas possuem mais de quatro filhos (ver Tabela 1). Sua origem familiar é a da classe trabalhadora, rural ou urbana, filhas de migrantes ou elas mesmas migrantes. Em termos de raça e cor, cinco são negras, cinco são brancas e uma é indígena. A faixa etária estende-se entre vinte até quarenta anos, sendo que cinco delas possuem entre 20 e 29 anos, três entre 30 e 39 anos e três entre 40 e 49 anos. Quanto à situação conjugal, nove são casadas em situação de cônjuge dependente e duas são separadas, chefes de família monoparental. A religião da maioria é a evangélica (ao todo seis), variando entre as pentecostais e as neopentecostais. Em termos de relação com os programas sociais, sete são usuárias e quatro são trabalhadoras de ponta (na Tabela, nomes em negrito): Noemi e Telma, agentes comunitárias de saúde da ESF e Elaine e Sara, agentes de proteção social do PAF. Entre as usuárias, três foram entrevistadas pela "porta de entra- 
Tabela 1 - Dados das entrevistadas por ordem etária

\begin{tabular}{|c|c|c|c|c|c|c|c|c|}
\hline Nome* & Idade & Filhos & Raça, cor & $\begin{array}{l}\text { Situação } \\
\text { conjugal }\end{array}$ & Educação & Religião & $\begin{array}{c}\text { Inserção } \\
\text { em } \\
\text { Programas }\end{array}$ & Distrito \\
\hline Jessica & 22 & 2 & Negra** & Coabitação & $\begin{array}{l}\text { Ensino médio } \\
\text { completo }\end{array}$ & Espírita & $\begin{array}{l}\text { ESF } \\
\text { PAF }\end{array}$ & CT \\
\hline Iara & 28 & 1 & Negra & Casada & $\begin{array}{c}\text { Ensino médio } \\
\text { supletivo }\end{array}$ & Evangélica & ESF & CT \\
\hline Valéria & 28 & 5 & Negra & Coabitação & $\begin{array}{c}\text { Ensino } \\
\text { fundamental } \\
\text { incompleto }\end{array}$ & $\begin{array}{c}\text { Não possui } \\
\text { (ex-evangélica) }\end{array}$ & $\begin{array}{l}\text { PAF } \\
\text { PBF }\end{array}$ & IT \\
\hline Vanessa & 28 & 4 & Negra & Coabitação & $\begin{array}{l}\text { Ensino } \\
\text { fundamental } \\
\text { incompleto }\end{array}$ & Não possui & $\begin{array}{l}\text { PAF } \\
\text { PBF }\end{array}$ & IT \\
\hline Elaine & 29 & 2 & Branca & Coabitação & $\begin{array}{l}\text { Ensino médio } \\
\text { completo }\end{array}$ & Evangélica & PAF & IT \\
\hline Clara & 32 & 4 & Branca & Separada & $\begin{array}{c}\text { Ensino } \\
\text { fundamental } \\
\text { incompleto }\end{array}$ & Evangélica & $\begin{array}{l}\text { ESF } \\
\text { PAF } \\
\text { PBF }\end{array}$ & IT \\
\hline Noemi & 36 & 4 & Negra & Coabitação & $\begin{array}{l}\text { Ensino médio } \\
\text { incompleto }\end{array}$ & Evangélica & ESF & CT \\
\hline Sara & 36 & 2 & Indígena & Separada & $\begin{array}{l}\text { Ensino médio } \\
\text { completo }\end{array}$ & Evangélica & PAF & IT \\
\hline Sandra & 43 & 1 & Branca & Casada & $\begin{array}{c}\text { Ensino médio } \\
\text { (magistério) } \\
\text { completo }\end{array}$ & Católica & ESF & CT \\
\hline Rosalina & 45 & 4 & Branca & Casada & $\begin{array}{c}\text { Ensino médio } \\
\text { supletivo }\end{array}$ & Evangélica & ESF & CT \\
\hline Telma & 42 & 5 & Branca & Casada & Ensino médio & & ESF & CT \\
\hline
\end{tabular}

*. Os nomes são fictícios.

** A raça ou cor negra inclui pretos e pardos

da” da ESF, com a intermediação de Noemi (Iara, Rosalina e Sandra) e quatro do PAF, com a intermediação de Sara para entrevistar Clara. Jessica, Valéria e Vanessa foram intermediadas por outros agentes de ponta. ${ }^{6}$

\footnotetext{
I $\quad$ Na construção de uma família respeitáจ vel, onde os homens devem exercer a função Фं de chefe de família e as mulheres a de dona ळ do lar, torna-se fator constituinte a dedicação fi integral à atividade doméstica das mulheres †े como esposas e (ou) mães, afastando-se do Fे mercado de trabalho. As partes que seguem i irão mostrar dispositivos que fazem com que $\therefore$ as mulheres permaneçam na posição social Nิ que lhes foi preparada no processo de moder-

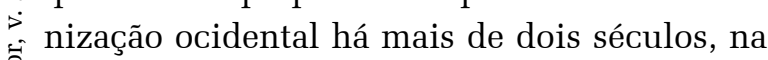
construção da categoria de assistidas e, mais ๙ึ especificamente, no Brasil contemporâneo, 牙 como beneficiárias.

\section{AS USUÁRIAS: construindo uma
família trabalhadora respeitável \\ AS USUARIAS: construindo uma
família trabalhadora respeitável}

Além do fato de as sete mulheres possuírem o ponto em comum de serem mães, usuárias de programas sociais, nenhuma delas trabalha. De trabalhadoras, com carteira assinada ou não, elas passaram, com o casamento e a maternidade, pelo processo de ordenamento de suas vidas, o que as colocou dentro da lógica da moral dos pobres, quer tomando como seu papel o cuidado familiar e doméstico de modo naturalizado, quer compelidas por atores externos (de modo mais direto, o companheiro ou o marido), que constantemente lembram que elas devem cuidar exclusivamente dos afazeres domésticos. Assim, Valéria conta que começou a estudar com uma senhora que oferecia aulas no bairro durante o dia, escondida do marido. Mas, como não conseguiu alguém para cuidar de seus filhos, não prosseguiu. Participou, também, de uma entrevista de trabalho cujo resultado foi positivo, mas terminou por abrir mão do emprego, pois seu companheiro Augusto não admite que sua companheira trabalhe fora de casa. Como explica Valéria, "é um ciúmes doentio, ele não deixa eu estudar, não deixa eu trabalhar, ele acha que se eu trabalhar eu vou arrumar outro, se eu for estudar eu vou namorar com o pro- 
fessor. Eu queria muito voltar a estudar, mas [...]". Contrariamente, as visitas domiciliares de um agente de proteção social não seria um problema, pois, segundo afirma Valéria, foi graças a ele que o recebimento do Programa Bolsa Família foi possibilitado (um valor de 65 reais mensais, em 2011). Além do benefício do programa de transferência de renda, Valéria frequenta as atividades de uma associação espírita na vizinhança para receber cesta básica a cada quinze dias.

Foi também o caso de Vanessa, sua irmã gêmea que, quando quis frequentar um curso (privado) de cabeleireiro, seu companheiro Maurício, que estava presente na primeira entrevista que realizei com ela, argumentou que ela deveria priorizar o trabalho doméstico:

É o que eu falo pra ela. Ela tem que ver, querer o seguinte: que tem casa, tem as crianças, eu tenho que trabalhar, hoje estou de folga, mas entro às duas no serviço, tenho que sair de casa no máximo até uma e meia. Então eu falo assim, procure fazer uma coisa que não interfira nas coisas em casa, porque eu acho que ela, como minha esposa, ela tem obrigação em casa, minha obrigação é colocar as coisas aqui (Maurício, 2011).

Seu companheiro admite, no entanto, que ela deve frequentar as oficinas oferecidas pelo Programa Ação Família, pois associa essas atividades ao benefício do programa de transferência de renda, que ele chama aqui de renda mínima. $^{7}$

Agora quando tem reunião, fala, ela fala que vai eu não falo nada porque como ajudou no início esse negócio do renda mínima que a gente tem, que ajuda a gente pra caramba, então as vezes tem reunião, eu falo: vai. Ela fala: preciso ir pra poder estar ciente do que está acontecendo. Então tá bom, continua... (id.)

As atividades fora de casa das irmãs são frequentemente legitimadas pelos seus respectivos parceiros somente a partir do momento em que podem ser provedoras de benefícios assistenciais.

${ }^{7}$ Para alguns, pode ocorrer uma confusão entre o Programa Bolsa Família e o Programa de Renda Mínima do município de São Paulo, mas Segundo Vanessa, ela recebe o Bolsa Família.
Outras, um pouco mais escolarizadas que Valéria e Vanessa, possuem a experiência do trabalho antes da maternidade. Iara trabalhava no mesmo ramo que seu marido, o de eventos, mas deixou o emprego depois que engravidou de sua filha. Foi "natural" para ambos ela parar de trabalhar e ele continuar. No início, seu marido ajudava nas tarefas domésticas, mas, com o passar do tempo, passou a fazê-lo esporadicamente. A divisão do trabalho é, ao mesmo tempo, aceita por Iara, que considera ser ela a responsável pelos afazeres domésticos.

Antes, quando ele morava sozinho, ele limpava tudo, a casa dele era impecável, eu falava - meu Deus ele caiu do céu pra mim; era limpinho. Depois que eu casei com ele, ele ainda me ajudava; depois que eu tive a menina, acabou. [...] Mas, se for, que nem ele estava de férias, ele lavava a louça. Agora, passar e lavar roupa, não. Ele passava uma vassoura na casa, limpar mesmo não é com ele. Eu acho que é minha obrigação (Iara, 2011).

Iara concebe uma condição diferente para sua filha, mas afirma ser grata ao marido por poder exercer a maternidade exclusiva:

Eu quero que, quando ela cresça, ela seja independente, não dependa de ninguém, eu vou sempre ensinar isso pra ela. Eu dependo do pai dela agora, mas eu quero ser independente também de todas as formas; sinto muita falta disso, trabalhar, pegar o meu dinheiro, de comprar o que eu quero. Ele compra tudo o que eu quero só que tem hora que cansa de pedir. Tem hora que fala - cansei, eu não quero mais depender de homem, é muito chato, sempre fui independente. Mas Mateus é um bom marido, apesar dos pesares é um bom marido.

O que é um bom marido pra você?

É um bom pai. É um homem que conversa, é compreensivo comigo, às vezes eu estou naqueles dias chatos, ele está entendendo. Um homem que entendi que eu decidi ficar três anos me dedicando à milha filha porque tem homem que cobra. Tem homem que fala - você tem que trabalhar pra ajudar em casa (Id.).

Diferente das três mulheres acima, fortemente resignadas com a dedicação exclusiva ao lar, Jessica não esconde sua irritação quanto à necessidade de ver sua vida se modificar 
drasticamente depois do nascimento de suas filhas gêmeas (hoje com um ano). Ela saiu do emprego, teve depressão pós-parto e passou pela obesidade, em contraste com o seu companheiro, que não viu sua trajetória se modificar, continuando no mesmo emprego. Ela percebe que o seu trabalho reprodutivo não é reconhecido:

O que eu falo pra ele é assim, eu reconheço o trabalho dele, eu reconheço que é cansativo, eu reconheço que pegar condução não é fácil, é difícil ir e voltar, acordar $5 \mathrm{~h}$ da manhã, é ruim, mas ele também tem que reconhecer o que eu faço, não é brincadeira. Eu vou dar banho em uma, fico de olho na outra porque quando eu vou dar banho na outra, a outra está quebrando não sei o que. Eu, qualquer hora, eu vou chegar no hospital e vou presa de tanto que essas meninas caem porque eu não consigo cuidar das duas ao mesmo tempo, uma vai pra um lado, a outra vai pro outro [...] (Jessica, 2010).

Diferentemente das mães da classe média, ela não tem como delegar a maternidade e, por ter baixa escolaridade e ser moradora de bairro distante do centro da cidade e estigmatizado, suas opções de obter um emprego que permita voltar ao bairro para pegar suas filhas na creche, a tempo, são limitadas. Nesse interim que aguarda um momento propício para reingressar no mercado de trabalho, ela frequenta as atividades do Programa Ação Família, que são oferecidas durante o dia, como a oficina de manicure. + posa e máe é importante para a dignidade das F mulheres da classe popular, tal posição social as coloca em profunda desigualdade em rela$\dot{2}$ ção a seus parceiros em termos econômicos e $\therefore$ sociais. Apesar de elas se ressentirem tal fato, - como é o caso de Jessica, desafiar e transgredir a ordem social e moral estabelecida requer uma inserção mais ou menos firme em uma rede social, o que permite se beneficiar da ajuda e da cumplicidade das pessoas pertencentes às instituições, que terminam por impulsionar para um passo adiante. Nesse sentido, é possível afirmar que as mulheres se encontram em uma situação de forte isolamento social. O cuidado que elas oferecem à família se torna sua razão de ser, e suas vidas se organizam em torno dessa função, numa construção paulatina da maternidade dentro da compreensão que elas têm sobre a importância desse papel para a formação da família. Isso ocorre não por possuírem elas vocação para a maternidade, mas porque, na naturalização dos papéis de gênero, em que o homem deve ser o provedor e a mulher a cuidadora do lar, não há outra pessoa que possa exercê-la em seu lugar do modo como se acredita que elas são capazes. Assim, elas terminam por exercer o que Molinier (2012, p. 36) chamou de "trabalho inestimável do care" (cuidado); caso contrário as crianças estariam abandonadas à sorte.

\section{A assistência como o lugar onde as subalternas podem atuar}

Algumas mulheres antes atendidas pelos programas assistenciais passaram a ser as próprias agentes de execução desses programas $^{8}$ (Georges e Santos, 2013). Nesta parte, procuramos desvendar como, a partir da condição de usuárias, elas ingressaram no sistema assistencial como trabalhadoras, e quais são os impactos da passagem do status de assistidas para agentes, nas suas relações sociais.

\section{De usuária a agente: saindo da "de- pressão futura"}

Noemi e Telma fazem parte de um contingente de 34 ACSs da Unidade Básica de Saúde (UBS) estudada, em que todas as agentes são mulheres. Elas estão distribuídas em seis equipes médicas da unidade. ${ }^{9}$ As ACSs

${ }^{8}$ Em outro estudo (Georges e Santos, 2013), analisamos as trajetórias das mulheres em termos de construção de uma carreira moral na assistência (em termos de H. Becker), desde as usuárias até as integrantes da direção da organização executora do PAF.

${ }^{9}$ Cada equipe da ESF deve ser coordenada por um enfermeiro e deve contar, além deste último, com um médico, 
são as profissionais da equipe médica da Estratégia Saúde Família (ESF) mais conhecidas e próximas da população. É fácil identificá-las na rua, pois vestem sempre um jaleco azul. Ao chegar à UBS de manhã, atualizam suas anotações, trocam informações com os demais membros da equipe e partem para as visitas domiciliares. As visitas são realizadas nos turnos da manhã e da tarde para cumprir a meta de 200 famílias por mês cada uma. Elas devem também organizar periodicamente as reuniões com grupos específicos de usuários, como o das crianças, das mulheres, das grávidas e dos hipertensos. Nessas reuniões, elas permanecem na função de auxiliar, sendo as palestras dadas pelas enfermeiras.

Noemi afirma ter ficado "parada” durante dez anos, antes de iniciar o trabalho de ACS. Com a maternidade (uma filha de 13 anos, um filho de 12, um filho de 11 e outro de 9), dedicou-se exclusivamente às funções domésticas. Ela sentia necessidade de trabalhar e se organizou para encontrar um serviço de trabalhadora doméstica, matriculando seus três filhos maiores na creche. No entanto, a distância entre Cidade Tiradentes e as áreas centrais da cidade, onde teria mais oportunidades de trabalho, e o fato de ser mãe de crianças ainda pequenas fizeram com que nunca obtivesse uma resposta positiva depois de uma entrevista. Em 2005, Noemi se submeteu a um processo seletivo. A seleção, realizada na igreja da Assembleia de Deus, consistia em uma prova escrita e uma dinâmica de grupo. Noemi comenta sobre o processo:

A prova escrita foi meio [...] Foi uma prova relacionada ao serviço mesmo do agente comunitário; então, quem não prestava atenção não conseguiu passar. Teve algumas questões incluídas de português, matemática, que era o básico, mais na área da saúde. E, no final, tinha uma redação que eles colocaram uma determinada situação de uma família, e aí você tinha que direcionar aquela família - se você fosse

dois auxiliares de enfermagem e seis ACSs. Na unidade estudada não encontramos nenhum profissional masculino que não fosse médico ou funcionário do setor administrativo. Havia constante falta de médicos nas equipes, chegando a haver apenas um entre as seis equipes durante um período de aproximadamente três meses. um agente comunitário como é que você ia direcionar essa família, como é que você ia orientar essa família? Uma família completamente desestruturada. Então, assim, eu não tinha a menor ideia da dinâmica do trabalho do agente comunitário, mas eu me pautei muito do que eu vi a minha agente fazendo na minha casa (Noemi, 2010).

Noemi foi selecionada porque, segundo o que lhe explicaram posteriormente, apesar de ela não ter falado muito na dinâmica, "porque eu tenho esse meu jeito assim, se eu não consigo espaço, então eu também não invado”, uma sondagem na vizinhança revelou que ela tinha uma boa relação com os vizinhos, e uma boa referência: "eu sempre fui muito discreta, não gostava de ficar enfiada na casa de ninguém e vice-versa”. A combinação entre o know how adquirido com sua experiência de usuária do serviço, o conhecimento de saber lidar com o que é chamado de "família desestruturada", conforme é normatizado pelo serviço, assim como sua postura discreta parece ter apontado para a aptidão de Noemi para exercer um trabalho especializado que requer cuidado, capacidade de orientar e sensibilidade de lidar com situações difíceis.

Ser selecionada para a contratação no serviço leva as agentes de rua à emancipação de uma vida confinada na esfera privada, depois de anos de maternidade e exclusividade na função de dona de casa. Telma, com quatro anos de experiência como ACS, viu sua situação se transformar por meio do trabalho de ACS:

Olhando pra trás, eu acho que esse emprego me tirou, bem dizer, de uma futura depressão, porque isso do meu marido ser à frente de tudo, eu estava ficando deprimida sem perceber porque tudo era ele, resolver as coisas era ele, tudo era ele. E depois que eu comecei a trabalhar, sabe quando você acorda pra vida? Eu estou viva, eu tenho que fazer alguma coisa. Eu me sinto eu, eu sou alguém, eu trabalho, eu sou uma cidadã. [...] Tem mulheres que leva assim numa boa [depender da renda do marido], não sente, mas eu descobri que estava me fazendo mal, no momento eu não percebia, eu percebi depois que eu arrumei emprego que aquilo estava me fazendo mal (Telma, 2010). 
Seu trabalho é também bem-vindo por seus cinco filhos adolescentes, que, ao sentirem falta da mãe, que fazia tudo por eles antes, passaram a organizar-se entre eles para realizar o trabalho doméstico. O trabalho produtivo da mãe transforma as relações familiares, igualmente em direção à autonomia de cada membro. Apenas seu marido, motorista de taxi, "ficou enciumado porque eu não peço mais dinheiro, eu resolvo, quando ele vai lembrar, eu já estou resolvendo, então ele fica incomodado". Na verdade, a informação sobre o trabalho de agente comunitário teria sido inicialmente levada ao marido, mas, por considerar um trabalho mais adaptado para as mulheres, ele mesmo sugeriu que Telma tentasse a seleção.

Em outros casais, como o de Noemi e seu marido, o fato de a mulher possuir um emprego estável faz surgir situações em que o homem se sente livre do papel de provedor. Graças à estabilidade da esposa, apesar de estar desempregado, o marido de Noemi passou a não mais aceitar qualquer vaga de emprego. Assim, ela se queixa da acomodação do marido, numa difícil equação entre a consolidação de sua autonomia e o que é prescrito para os homens no meio popular:

Não entra na minha cabeça porque o fato de eu estar aqui há cinco anos, a gente poderia estar numa situação melhor, mas, desde que eu entrei, ele mudou a postura dele em relação a isso, então ele escolhe mais, recusa mais porque ele sabe que eu tenho uma certa segurança aqui. É também ilusório, pode ser que amanhã ou depois [...] (Noemi, 2010).

O trabalho de ACS surge como um lugar onde a relação conjugal e a familiar podem se modificar a favor da mulher, quando encarado com tolerância por parte do companheiro. ลิ Os papéis de gênero da classe popular podem igualmente se reverter como é o caso de Noemi, em que seu marido se tornou mais seletivo para obtenção de emprego. Ademais, o respeito obtido pela família estende-se à esfera pública, como em relação à vizinhança e em relação à equipe médica, pois seus relatórios sobre as famílias cadastradas passam a compor dados que são levados às instâncias superiores. Como afirma Telma: "diz o povo que nós somos a base do PSF. E é isso que a gente é mesmo. Eu particularmente analiso que é assim para o PSF andar, sem o agente comunitário é impossível. [...] Isso que faz a diferença tanto para as pessoas quanto para a equipe de saúde." (Telma, 2010).

Tal função-chave das ACSs é levada ao extremo, a ponto de haver um ofuscamento das fronteiras entre o privado e o público nas horas em que elas terminam a jornada de trabalho. A vizinhança "não separa a pessoa Noemi da agente comunitária; essa é uma queixa de todas nós; então você tem que estar à disposição sempre, sábado, domingo, feriado pra você dar uma orientação, porque eles sabem de tudo, eles sabem como funciona, mas, assim, você tem que dar atenção". Ela deve também, como ACS, lidar com a frustração dos usuários quanto à ausência dos médicos e agir com o mínimo de dependência do médico e a máxima autonomia e confiança. Ela explica:

Não é depender do profissional médico [...] É de você estar prestando atenção nas orientações que a gente faz, para usar o posto de maneira correta, para você conseguir a resposta que você quer com a agilidade que você quer. (Noemi, 2010).

Vocês são um pouco... Psicólogos... E aí a gente deixa falar. Eu pelo menos tenho essa postura de deixar a pessoa falar, depois que a pessoa termina, assim, eu não tenho problema nenhum, às vezes, de passar algumas coisas que eu também enfrento (id.)

A proximidade entre ela e os usuários é facilitada por meio de uma sociabilidade religiosa já existente entre eles, como relação de vizinhança, quando ambos, crentes, trocam termos e mensagens que fazem referência ao cristianismo, à fé compartilhada entre eles. ${ }^{10}$

${ }^{10}$ Assistimos recentemente, no Brasil, a uma ascensão sem precedentes dos evangélicos (ultrapassando 22\% da população, segundo o Censo Demográfico de 2010), e é possível encontrar uma grande proporção de fiéis do sexo feminino, como ocorre na Igreja Universal do Reino de Deus IURD (Santos e Rosas, 2014). A religião que mais cresceu na camada popular não foi aquela que endereçou questões vinculadas à esfera pública ou política, como o catolicismo da Teologia da Libertação, atuante nas periferias entre os anos 60 e 90, mas sim a que passou a propor a superação dos problemas individuais e (ou) familiares, como os 
O espaço da assistência parece surgir como um espaço onde "os subalternos podem falar" (Spivak, 2010) e onde uma "voz diferente" (Gilligan, 2009) é escutada como a voz legítima. O trabalho das agentes de ponta consiste em escutar as usuárias e transmitir suas demandas aos gestores da saúde e da assistência. Telma assume seu trabalho não somente para "cuidar" das usuárias "prioritárias", mas de todas que necessitam ser escutadas:

Às vezes, tem uma visita que a pessoa não é hipertensa, a pessoa não é diabética, não é um acamado, não tem nenhuma prioridade na residência, mas, no momento que você chega, a pessoa está deprimida, ela quer que você olhe nos olhos, ela quer ouvir você falar, ela quer desabafar pra você, ela não é hipertensa, mas ela está com alguma coisa lá dentro que ela quer [...] (Telma, 2010).

\section{Possuir o perfil: o trabalho assisten- cial como vocação}

A equipe de agentes de ponta do programa Ação Família, onde Carla e Sara exerciam a função de agentes de proteção social, era menor do que a da ESF, composta por oito agentes de rua no total. Elas trabalhavam sob a supervisão direta de uma técnica. ${ }^{11}$ Vestiam, como as ACSs, um jaleco, mas de cor verde, que simbolizava suas funções de trabalhadoras sociais da prefeitura (embora tenham sido contratadas pela ONG conveniada), para atender a 150 famílias por mês, realizando visitas domiciliares matinais todos os dias. À tarde atualizavam seus relatórios e participavam de reunióes de equipe. Organizavam, também, reuniões socioeducativas com as famílias usuárias, uma vez por mês, permanecendo na função de apoio às palestras dadas por um técnico.

Sara, migrante de Corumbá, Mato Grosso do Sul, iniciou o trabalho assistencial primei-

vícios, as relações conjugais e a sexualidade (Mariano id.; Machado 2005; Couto 2002 : 359).

${ }^{11}$ A equipe técnica do PAF da unidade estudada era formada por duas assistentes sociais, um psicólogo e uma pedagoga. Uma gerente, formada em serviços sociais, administrava a unidade. ramente como voluntária. Depois do divórcio, por volta de 2003 , uma vizinha que a ajudava frequentemente apresentou-lhe certo dia uma pastora de uma igreja evangélica influente na zona leste de São Paulo. Sara cadastrou-se no programa do governo do estado de distribuição de alimentos para famílias cujo chefe é desempregado e, de modo a retribuir, começou a trabalhar como voluntária para a fundação ligada à referida igreja, que realizava ações filantrópicas. Ela avaliou que o assistencialismo era "muito ruim para a vida de uma pessoa", considerando que deveria oferecer sua ajuda como contrapartida. Além do trabalho voluntário que prestou à organização, converteu-se à igreja. Pouco tempo depois, foi convidada para trabalhar como educadora de crianças atendidas pelo Programa Crescer, desenvolvido também pela fundação da igreja em questão, que funcionava na mesma sede da unidade do PAF estudada nesta pesquisa. As crianças atendidas eram moradoras do setor onde Sara atuou como APS: "As crianças vinham, almoçavam, tomavam o café da tarde e iam embora; é mais assistencialismo". Mais tarde a fundação obteve um convênio com a prefeitura para executar o Programa Ação Família (2007). Sara soube do recrutamento de agentes de proteção social pelo jornal e viu que se "encaixava no perfil", pois era preciso conhecer a comunidade onde mora. Assim, Sara relata:

Há uns meses atrás, eu, lendo o jornal, eu vi que ia ter essa seleção de APS e dentro do que eu estava lendo, eu vi que eu me encaixava no perfil, conhecer a comunidade, conhecer o local onde eu moro, e era só fazer a inscrição, no centro de referência. $\mathrm{Eu}$ estava de férias em julho daqui, das crianças, eu peguei e fui pra lá, falei - eu vou. Chegando lá quem estava lá era o pessoal da Fundação, fazendo inscrição, mas eu fui, eu falei - eu vou fazer porque eu não aguento mais ficar com as crianças, não é o objetivo que eu quero. Daí eu fiz, fiz a seleção, fiz as provas, daí eu fiquei como APS (Sara, 2010).

A prova consistia em conhecer o material do Programa Ação Família. Segundo Sara, ele "não é difícil de entender", mas a pessoa deve ter o "perfil", "vestir a camisa". Se Sara julga, 
por vezes, as usuárias com olhar moralizador, é porque ela se considera uma caminhante no processo de transformação relativamente bem sucedido. Estava na mesma condição que muitas das mulheres cadastradas sob sua responsabilidade: chefe de família sem cônjuge, com dois filhos, sem trabalho, recebendo cesta básica e outras ajudas. Mais para trás, saiu de uma cidade que ela chama de subdesenvolvida, Corumbá, e um contexto familiar marcado pela violência, principalmente na linhagem de sua mãe. Sua história familiar é de violência imposta às mulheres, desde sua avó indígena, que foi "pega no laço" pelo seu avô e escravizada. Sua mãe sempre se incomodou com a presença dos próprios filhos e dizia-lhes que deveriam ir embora de casa. Apesar de o elemento religioso não aparecer espontaneamente nas palavras de Sara, ela se descreve como alguém que possui uma vocação para o trabalho social, adotando fortemente as normas de conduta prescritas pela direção da organização que a emprega, baseadas no esforço da transformação, numa postura proativa. ${ }^{12}$ Isso se reflete na recusa de tudo o que é atrasado, como aceitar a caridade e promover o assistencialismo. Sara é sempre motivada pelo que é desenvolvido, e sua postura diante da vida deve ser também “avante", como disse.

Um caso que se contrapõe à "carreira” social de Sara é o de Elaine, que terminou por ser demitida apenas três meses depois de ter sido contratada pelo PAF. Apesar de já ter trabalhado como voluntária em um centro de recuperação de dependentes químicos, dirigido por seu tio, pastor, ela não interiorizou o trabalho social como uma vocação do mesmo \& modo que Sara. Sua relação com o ex-marido

N ${ }^{12}$ Sobre a construção da carreira das mulheres que compõem a direção da organização contratante, ver Georges e Santos, 2013. Segundo a gerente da unidade do PAF pesquisada, a estória "que mais ilustra como o Programa Ação Família faz diferença na vida das pessoas", é, como contou, o caso de uma mãe de uma família que está em depressão, não cuida dos filhos e, passando a receber a visita dos APSs, começa a ser convidada a participar das oficinas e reunióes socioeducativas. Nesse processo de sair de casa e ter contato com outras pessoas que vivem uma experiência similar, a usuária supera a depressão e passa a adquirir a vontade de adotar iniciativas transformadoras. exercendo plenamente sua cidadania. e com o atual companheiro tem sido fortemente igualitária. O divórcio foi decidido em comum acordo entre o casal, por terem chegado à conclusão de que a relação era mais baseada em amizade do que em atração entre homem e mulher.

\begin{abstract}
Na verdade, não teve discussão, não teve briga, não teve nada, a gente sentou e conversou, a gente descobriu que a gente se gostava muito mais como amigo do que como marido e mulher; a gente era praticamente irmãos na mesma casa, a gente morava na mesma casa porque [...] Eu acho que como a gente se conheceu muito cedo, e a gente logo em seguida casou, então a gente não teve tempo pra se conhecer direito, foi se conhecendo no dia a dia, e a gente descobriu que a gente não se gostava como marido e mulher (Elaine, 2011).
\end{abstract}

Elaine e seu ex-marido compartilharam a guarda do filho, de modo que o pai permaneça com ele durante a semana e Elaine o encontre nos finais de semana e nas férias. Tal arranjo familiar permitiu que ela se concentrasse no trabalho após o divórcio, ajudando a tocar o ateliê de costura de sua mãe, entregando encomendas com o seu carro. Quando era casada, trabalhou como auxiliar administrativa em uma empresa de vendas de autopeças. Após juntar-se com o atual companheiro, abriu, ao lado da casa de sua sogra, uma bomboniere, que acabou não dando certo em pouco tempo. Ficou desempregada até que sua sogra, atendida pelo PAF, informou-lhe sobre uma vaga aberta pelo programa.

Sobre seu companheiro, feirante, de nível de instrução mais baixo do que o seu, ela se posiciona quando explica que ele é uma pessoa ciumenta:

É que eu não dou muita asa para ele, eu não falei pra você que eu sou bem mandona? Não dou muita asa pra ele, porque se eu deixar... [...] Mas eu falei pra ele - deixa eu te explicar uma coisa amor. Quando a gente se conheceu, eu já tinha uma vida, não vou parar a minha pra viver a sua, infelizmente não; antes disso acontecer, eu largo você, e vou viver sozinha; já estou te explicando, é melhor parar [...] (Elaine, 2011). 
Nesse sentido, Elaine não interiorizou a ética assistencial e familiar prescrita no programa, quebrando suas regras e, assim, foi rotulada como desprovida do "perfil" para executar o trabalho de controle dos usuários (Becker, 1991, p. 10). Por outro lado, por suas experiências de trabalho e pelo modo como conduziu o divórcio, Elaine está fora de uma perspectiva assistencial, o que contrasta com Sara que, após a separação, criou sozinha seus filhos, necessitando de ajuda. É possível inferir também que, de modo contrastante com as outras agentes, a trajetória de Elaine aponta para outra lógica nas relações de gênero, aquela que transgride a moral dos pobres construindo uma relação não hierarquizada com seus parceiros e deixando de construir uma identidade feminina baseada na maternidade. Assim, ela não foi capaz de adotar a identidade de trabalhadora social esperada pelos programas "familistas”, em que as próprias agentes devem reproduzir as relações tradicionais de gênero tanto na sua organização familiar privada como no discurso como profissional no espaço público. Nesse sentido o trabalho de agente do PAF foi, para Elaine, uma experiência acidental, já que a assistência não constituiu em lugar de emancipação para uma pessoa já emancipada.

\section{CONCLUSÃO}

Percorremos, neste artigo, as relações que as mulheres que compõem a população focalizada pelos "novos" programas sociais constroem com a família e o trabalho, e formam uma configuração de gênero conservadora que fundamenta o bom funcionamento dos programas familistas. Tal relação entre Estado e as famílias pobres, passando pela intermediação das mulheres, encontra sua origem no processo de modernização ocidental, numa normatização das famílias da classe trabalhadora. No Brasil, a organização familiar dos pobres tem se baseado na divisão dos papéis entre os sexos como ideal, onde o homem é o chefe de família e a mulher, dona do lar, para alcançar um projeto familiar conjunto. Hoje, apesar da massiva ocupação no mercado de trabalho, as mulheres da classe popular encontram resistência do companheiro para participar de atividades na esfera pública. Da mesma forma, elas fazem parte do segmento da classe trabalhadora precária, para quem as possibilidades de emprego são praticamente inexistentes. $\mathrm{Na}$ ausência de uma ocupação a seu alcance, algumas terminam, como se viu em nossa pesquisa de campo, por encontrar sua razão de ser na função materna; outras o fazem por não haver possibilidade de delegação do cuidado.

Algumas usuárias ou familiares de usuárias dos programas e serviços assistenciais lograram obter um emprego como agentes de ponta - ocupação relativamente nova na paisagem urbana das periferias -, pois não encontraram particular resistência por parte dos companheiros, quando casadas. É possível afirmar que as usuárias que se tornaram agentes foram as maiores beneficiárias dos "novos" programas sociais. De maneira contrastante, foi possível identificar, para as usuárias, dois movimentos positivos, porém em intensidade distinta: de um lado, ocorreu uma importante emancipação no espaço privado; de outro, certo grau de avanço no espaço público. As ACS, situadas no nível mais baixo da hierarquia da equipe médica, sentem-se mais fortalecidas em relação ao companheiro, primeiro pela independência financeira proporcionada, e, em consequência, pelos efeitos subjetivos trazidos pelo trabalho, numa constatação de ter conquistado a cidadania, como foi afirmado por Telma. Os "novos" programas sociais, que compreendem a ocupação de agentes de ponta, representam um nicho de trabalho onde as mulheres subalternas podem atuar e galgar uma carreira quando interiorizam a ética do cuidado e um espírito proativo, como bem demonstra Sara.

De outro lado, a aceitação de exercer ocupações nas condições muito particulares impostas pelos programas - impossibilidade 
de exercer o trabalho além da microárea onde reside, indefinição de fronteiras entre as horas de trabalho e extratrabalho, recebendo como remuneração um salário mínimo - representa um alto custo para as mulheres. A naturalização do voluntarismo das mulheres pobres pelos "novos" programas sociais termina por proporcionar o máximo de produtividade para as instituições gestoras dessas iniciativas (Santos e Rosas, 2014). Na autoapresentação que as agentes estabelecidas, como Noemi, Telma e Sara, realizam, é possível entrever que possuem o "perfil" apropriado para fazer face aos complexos problemas que surgem entre as famílias pobres que não possuem recursos alternativos para tratar as questões que afligem os indivíduos modernos e urbanos. Forma-se, assim, uma afinidade entre a "moral dos pobres" e as políticas familistas, na qual as últimas se alimentam da primeira para se desenvolver. Se há certo espaço de fortalecimento da cidadania das mulheres pobres nas esferas pública e privada por meio da atuação, principalmente profissional, na assistência, o ganho maior da mobilização das mulheres como interface do Estado e das famílias focalizadas é atribuído ao governo local e ao nacional, assim como às organizações gestoras dos programas sociais que podem contar com uma alta produtividade das mulheres com um gasto bastante reduzido.

Recebido para publicação em 10 de agosto de 2014

\section{REFERÊNCIAS}

- ANDERSON, J. Formas de Pobreza y Estrategias Municipales. Isis Internacional, Santiago: Ediciones de las Mujeres, n. 26. 1998.

BIRMAN, P. Mediação feminina e identidades pentecostais, Cadernos Pagu, Campinas, UNICAMP, n. 6-7, p. 201-226. 1996.

COUTO, M.T. Na trilha do gênero: pentecostalismo e CEBs, Revista de Estudos Feministas, UFSC, Florianópolis, n. 10, p. 357-369. 2002

DAGNINO, E.; OLIVEIRA A. J. e PANFICHI, A. (Orgs.) A disputa pela construção da democrática na América Latina. São Paulo: Paz e Terra. 2006..

DAGNINO, E Cultura, cidadania e democracia A transformação dos discursos e práticas na esquerda latinoamericana. In: ALVAREZ, S.; ; ESCOBAR, A. (Orgs.). Cultura e política nos movimentos sociais latinoamericanos. Belo Horizonte, Editora UFMG, 2000, p. 61102

DEMAZIERE, D.; DUBAR, C. Analyser les entretiens biographiques. L'exemple de récits d'insertion. Saint Nicolas (Québec): Les Presses de l'Université Laval. 2007.

DONZELOT, J. La police des familles. Paris: Les Editions de Minuit. 1977/2005.

DUBOIS, V. Le paradoxe du contrôleur. Incertitude et contrainte institutionnelle dans le contrôle des assisté sociaux. Actes de la Recherche en Sciences Sociales, Paris, n. 178, Seuil, p. 28-49. 2009

FELTRAN, G. Fronteiras de tensão. Política e violência nas periferias de São Paulo. São Paulo: Editora Unesp/Centro de Estudos da Metrópole, 2011. p.358.

FOUCAULT, M. Microfísica do poder. Rio de Janeiro: Paz e Terra, 1979/2004. p. 295

GEORGES, I. Entre participação e controle: os(as) agentes comunitários de saúde da região metropolitana de São Paulo, Sociedade e Cultura, Goiânia, v. 14, n. 1, jan./jun. p. 73-85. 2011.

GEORGES, Isabel; SANTOS, Yumi Garcia dos. A produção da demanda: viés institucional e implicacões políticas da terceirização do trabalho social na periferia de São Paulo. In: CUNHA, N.; FELTRAN, G. (Orgs.) Sobre Periferias. Novos conflitos no Brasil contemporâneo. Rio de Janeiro: Lamparina, 2013. p. 159-177.

GILligAN, C. Une voix différente. Pour une éthique $d u$ care. Paris: Flammarion, 2008.

JENSON, J. Politiques Publiques et Investissement Social: Quelles Conséquences pour la Citoyenneté Sociale des Femmes? Cahiers du Genre, CNRS-GTM, Paris, hors-série, p.21-43. 2011

LIMA, J.; MOURA, M. do C. Trabalho Atípico e Capital Social. Os Agentes Comunitários de Saúde na Paraíba. Sociedade e Estado, Brasília, v. 20, n. 1, p. 103-133, jun./ abr. 2005 .

LAVALLE, A. G. et al. Protagonistas da Sociedade Civil Redes e Centralidades de Organizações Civis em São Paulo. DADOS - Revista de Ciências Sociais, Rio de Janeiro, v. 50, n. 3, p. 465-498. 2007.

LIMA, J.C.; COCKELL, F. F. As novas institucionalidades do trabalho no setor público: os agentes comunitários de saúde. Trabalho, Educação, Saúde, v. 6, n. 3. p. 481-501. 2008.

MACHADO, M.D.C. Representacões e Relacões de Gênero nos Grupos Pentecostais. Revista de Estudos Feministas, UFSC, Florianópolis, v. 13, n. 2, p. 387-396. 2005.

MARIANO, R. Sociologia do crescimento pentecostal no Brasil: um Balanço. Perspectiva Teológica, v. 43, n. 119, p. 11-36. 2012.

MINISTÉRIO DA SAÚDE. Estratégia Saúde Família. Disponível em http://dab.saude.gov.br/portaldab/ape_esf. php. Acesso em: março de 2012.

MINISTÉRIO DO DESENVOLVIMENTO SOCIAL E COMBATE A FOME a. Bolsa Família. Disponível em http://www.mds.gov.br/bolsafamilia. Acesso em: janeiro de 2014

MINISTÉRIO DO DESENVOLVIMENTO SOCIAL E COMBATE À FOME b. Disponível em: file:///Users/yumi/ Downloads/PAIF_Tipificacao.pdf. Acesso em: janeiro de 2014.

MOLYNEUX, M. Mothers at the service of the New Poverty Agenda: Progresa/Oportunidades, Mexico's Conditional Transfer Programme. Social Policy and Administration, v. 40, n. 4, p. 425-449. 2006. 
MOLINIER, P. Ética e trabalho do care. In: Hirata, H. e Guimarães, N. (Orgs.) Cuidado e cuidadoras. As várias face do trabalho do care, São Paulo: Atlas, 2012. p. 166-182.

RAGO, M. Do cabaré ao lar. A utopia da cidade disciplinar. Brasil 1890-1930. Rio de Janeiro: Paz e Terra. 1985.

ROCHA, S. Pobreza no Brasil. Afinal, de que se trata? Rio de Janeiro: Editora FGV. 2006.

SANTOS, W. G. dos. Cidadania e justiça: política social na ordem brasileira. Rio de Janeiro: Ed. Campos, 1979. 138p.

SANTOS, Y.G. dos. A gestão sexuada do social: os novos programas sociais na saúde e na assistência e reprodução das relações tradicionais de gênero. Relatório de pesquisa (Pós-doutorado). 2012. p. 174. Relatório de pós-doutorado - Centro de Estudos da Metrópole/FAPESP.

SANTOS, Y. G.D.; ROSAS, N. As Mulheres nas Novas Políticas Sociais e na Assistência Neopentecostal. Novas Possibilidades de Emancipação ou Reprodução da
Desigualdade? In: GEORGES, I.; CABANES, R. Dossiê. Brésil(s). Sciences Humaines et Sociales, EHESS, Editions de la Maison des Sciences de l'Homme, Paris, n.6. 2014.

SARTI, C. A Família como Espelho: um estudo sobre a moral dos pobres na periferia de São Paulo, São Paulo, Autores Associados. 1996.

SEN, Amartya K. Gender and Co-operative Conflicts. In: TINKER, Irene (Org.). Persistent Inequalities. Oxford: Oxford University Press. 1990. p. 123-149.

SPIVAK, G. Pode o subalterno falar? Belo Horizonte: Editora UFMG, 2010. p. 133.

SPOSATI, A. Vida urbana e gestão da pobreza. São Paulo: Cortez Editora. 1988.

TATAGIBA, Luciana. Os desafios da articulação entre sociedade civil e sociedade política sob o marco da democracia gerencial. O caso do Projeto Rede Criança em Vitória/ES. In 


\section{WOMEN AS THE STRENGTH BEHING SOCIAL PROGRAMS}

\author{
Yumi Garcia dos Santos
}

This article examines how public policies for health and social care in Brazil are consolidated with the actions of poor women. Through a qualitative research and analysis of the trajectories of these users and top agents of the so called "new" Brazilian social programs, I intend to show that the success such programs have achieved is largely due to the work of these women, who are mediators within the conservative logic of a gender bias division of labor and denomination of women as caregivers In particular, the agents, as opposed to the users, have access to social mobility that frees them from the confinement of their private sphere by being present in the labor market. However, this female mobilization, with low costs and high productivity, benefits mainly the institutions of the "new" social programs in question, from philanthropic organizations to governmental ones.

KEYwORDs: "New" social programs. Feminine mediation. Family. Work. Gender bias labor division.
LES FEMMES COMME PILIERS DE LA CONSTRUCTION DES PROGRAMMES SOCIAUX

\author{
Yumi Garcia dos Santos
}

Cet article analyse comment les politiques publiques en matière de santé et d'aide sociale au Brésil se consolident à partir de la centralité d'action des femmes pauvres. Grâce à une recherche qualitative et à une analyse de la trajectoire des utilisatrices et des agents des dits "nouveaux" programmes sociaux brésiliens, notre intention est de montrer que le succès de ces programmes dépend en grande partie de l'action de ces femmes médiatrices au sein d'une logique conservatrice de la division sexuelle du travail et d'un enclin féminin pour les soins. Les agents, en opposition aux usagers, ont tout particulièrement accès à la mobilité sociale qui les sort du confinement de la sphère privée par leur présence sur le marché du travail. Cependant le résultat le plus important, obtenu grâce à cette mobilisation féminine à faible coût mais dont la productivité est élevée, bénéficie les institutions qui gèrent ces "nouveaux" programmes sociaux en question, allant des organisations philanthropiques aux gouvernements.

MOTS-CLÉS: “Nouveaux” programmes sociaux. Médiation féminine. Famille. Travail. Division sexuelle du travail.

Yumi Garcia dos Santos - Doutora em sociologia. Professora Adjunta do Departamento de Sociologia da Universidade Federal de Minas Gerais (UFMG). Com ênfase em relações de gênero, suas pesquisas tratam transversalmente os temas família, pobreza, políticas sociais e migrações. Publicações recentes: Assistência e família na América Latina: vínculos sociais, intimidade e gênero. Cadernos de Pesquisa (Fundação Carlos Chagas. Impresso), v. 44, p. 264-269, 2014; Olhares cruzados: relações de cuidado, classe e gênero. Tempo Social (USP. Impresso), v. 1, p. 47-60, 2014; Família, trabalho e religião das mulheres assistidas em São Paulo. Cadernos de Pesquisa (Fundação Carlos Chagas. Impresso), v. 44, p. 400-421, 2014; Les femmes dans les nouvelles politiques sociales et l assistance néopentecôtiste. Possibilités démancipation ou reproduction des inégalités?. Bresil(s), v. 1, p. 75-97, 2014. 